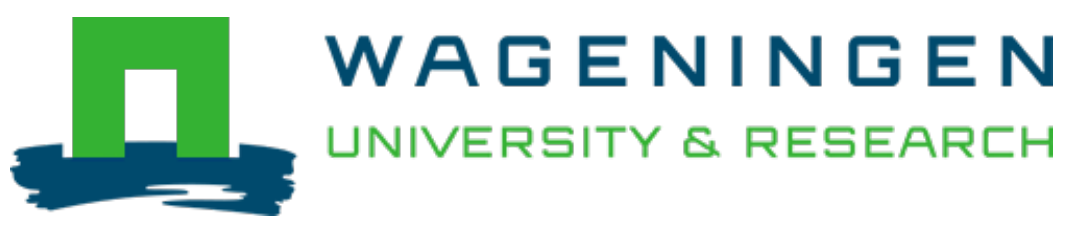

\title{
Monitoring the ecology of Bacillus during Daqu incubation, a fermentation starter, using culture-dependent and culture-independent methods
}

\author{
Journal of Microbiology and Biotechnology \\ Zheng, Y.; Zheng, X.; Han, B.Z.; Han, J.S.; Nout, M.J.R. et al \\ https://doi.org/10.4014/jmb.1211.11065
}

This publication is made publicly available in the institutional repository of Wageningen University and Research, under the terms of article $25 \mathrm{fa}$ of the Dutch Copyright Act, also known as the Amendment Taverne. This has been done with explicit consent by the author.

Article 25 fa states that the author of a short scientific work funded either wholly or partially by Dutch public funds is entitled to make that work publicly available for no consideration following a reasonable period of time after the work was first published, provided that clear reference is made to the source of the first publication of the work.

This publication is distributed under The Association of Universities in the Netherlands (VSNU) 'Article $25 \mathrm{fa}$ implementation' project. In this project research outputs of researchers employed by Dutch Universities that comply with the legal requirements of Article $25 \mathrm{fa}$ of the Dutch Copyright Act are distributed online and free of cost or other barriers in institutional repositories. Research outputs are distributed six months after their first online publication in the original published version and with proper attribution to the source of the original publication.

You are permitted to download and use the publication for personal purposes. All rights remain with the author(s) and / or copyright owner(s) of this work. Any use of the publication or parts of it other than authorised under article $25 \mathrm{fa}$ of the Dutch Copyright act is prohibited. Wageningen University \& Research and the author(s) of this publication shall not be held responsible or liable for any damages resulting from your (re)use of this publication.

For questions regarding the public availability of this publication please contact openscience.library@wur.nl 


\title{
Monitoring the Ecology of Bacillus During Daqu Incubation, a Fermentation Starter, Using Culture-Dependent and Culture-Independent Methods
}

\author{
Yan, Zheng ${ }^{1}$, Xiao-Wei Zheng ${ }^{1,2}$, Bei-Zhong Han ${ }^{1}$, Jian-Shu Han ${ }^{3}$, M. J. Robert Nout ${ }^{2}$, and Jing-Yu Chen ${ }^{1 *}$ \\ ${ }^{1}$ College of Food Science and Nutritional Engineering, China Agricultural University, Beijing, China \\ ${ }^{2}$ Laboratory of Food Microbiology, Wageningen University, Wageningen, The Netherlands \\ ${ }^{3}$ Technology Center, Shanxi Xinghuacun Fenjiu Distillery Co. Ltd., Fenyang, Shanxi, China
}

Received: November 22, 2012 / Revised: January 18, 2013 / Accepted: January 20, 2013

$D a q u$, a traditional fermentation starter, has been used to produce attractively flavored foods such as vinegar and Chinese liquor for thousands of years. Although Bacillus spp. are one of the dominant microorganisms in Daqu, more precise information is needed to reveal why and how Bacillus became dominant in Daqu, and next, to assess the impact of Bacillus sp. on Daqu and its derived products. We combined culture-dependent and culture-independent methods to study the ecology of Bacillus during Daqu incubation. Throughout the incubation, 67 presumptive Bacillus spp. isolates were obtained, 52 of which were confirmed by $16 \mathrm{~S}$ rDNA sequencing. The identified organisms belonged to 8 Bacillus species: $B$. licheniformis, B. subtilis, B. amyloliquefaciens, B. cereus, B. circulans, B. megaterium, B. pumilus, and $B$. anthracis. A primer set specific for Bacillus and related genera was used in a selective PCR study, followed by a nested DGGE PCR targeting the $\mathrm{V} 9$ region of the $16 \mathrm{~S}$ rDNA. Species identified from the PCR-DGGE fingerprints were related to $B$. licheniformis, B. subtilis, B. amyloliquefaciens, B. pumilus, $B$. benzoevorans, and $B$. foraminis. The predominant species was found to be $B$. licheniformis. Certain $B$. licheniformis strains exhibited potent antimicrobial activities. The greatest species diversity occurred at the Liangmei stage of Daqu incubation. To date, we lack sufficient knowledge of Bacillus distribution in Daqu. Elucidating the ecology of Bacillus during Daqu incubation would enable the impact of Bacillus on Daqu to be accessed, and the quality and stabilization of Daqu-derived products to be optimized.

Key words: Microbial ecology, Bacillus, fermentation starter, Daqu, PCR-DGGE

\footnotetext{
*Corresponding author

Phone: +86-10-62737966; Fax: +86-10-62737078;

E-mail: chenjy@cau.edu.cn
}

$Q u$ is a traditional fermentation starter, commonly used in Asia to ferment a variety of cereal substrates. The fermentation process produces foods with attractive flavors, such as vinegar, Chinese liquor, soy sauce, and rice wine. Daqu, a type of grain $Q u$, has been used for thousands of years [38]. Daqu is typically made from raw barley and pea, incubated under uncontrolled conditions without adding defined starter microorganisms. Daqu incubation is commonly divided into seven stages: Woqu (WQ), Shangmei (SM), Liangmei (LM), Chaohuo (CH), Dahuo (DH), Houhuo $(\mathrm{HH})$, and Yangqu (YQ). The entire incubation period is about one month [22]. Following the incubation, Daqu is further fermented by mixing with cooked cereals at a proportion of approximately 9-10\%. Previous cultureindependent and culture-dependent studies have revealed the presence of yeasts, molds, bacteria, and actinomycetes in Daqu. Of these, the bacteria, especially thermophilic Bacillus, are present in higher numbers than fungi [22, 25, 37]. Although Bacillus spp. are among the dominant microorganisms in Daqu (up to 7-8 log CFU/g) [37,38], more precise information is needed to reveal why and how this situation evolved. Armed with this knowledge, the impact of Bacillus on Daqu and its derived products can be evaluated.

Bacillus spp. are ubiquitous spore-forming bacteria associated with a variety of food products $[1,14,21]$. Usually, they are implicated in spoilage of food products and cases of food poisoning [3]. They are also used to produce commercial enzymes, such as amylases, proteases, amd lipases. Indeed, enzyme production by Bacillus may play a role in traditional food fermentation [11, 17, 18].

In this study, we combined culture-dependent and culture-independent methods to investigate the ecology of Bacillus throughout Daqu incubation. To more precisely identify the organisms involved, a nested-PCR was used, targeted specifically at the 16S rDNA genes of Bacillus and related genera. The antimicrobial spectra of certain 
Bacillus strains were also tested in order to confirm the nature of their dominance distribution. The results of this study may assist in improving the quality and stabilization of Daqu-derived products.

\section{Materials AND MethodS}

\section{Sampling}

The Daqu samples used in this study were collected in October 2009 from the Shanxi Xinghuacun Fenjiu Distillery Co. Ltd. (Fenyang, Shanxi, China). Each Daqu block is approximately $27.5 \times 16 \times$ $5.5 \mathrm{~cm}^{3}$ and weighs about $1.7 \mathrm{~kg}$. Daqu was produced and matured in stacked layers by traditional methods. Samples were collected at the end of the WQ, SM, LM, CH, DH, HH, and YQ stages. The temperatures of the samples were recorded by a mini infrared thermometer gun (UNI-T UT301A, Beijing) at the time of sampling. Samples were randomly selected from each upper, middle, and lower stacked layer, and ground and pooled to provide an experimental Daqu powder sample. For culture-based investigations, the samples were stored at $4^{\circ} \mathrm{C}$ and analyzed within $48 \mathrm{~h}$. For culture-independent investigations, the samples were stored at $-20^{\circ} \mathrm{C}$ prior to further analyses.

\section{Enumeration and Isolation}

Culture-based microbiological investigations were conducted at all seven stages of Daqu incubation. Ten grams of powdered sample was added to $90 \mathrm{ml}$ of sterile PPS (peptone physiological salt) solution containing $1 \mathrm{~g} / \mathrm{l}$ peptone (Oxoid LP0034; Oxoid, Basingstoke, Hampshire, UK) and $8.5 \mathrm{~g} / \mathrm{l} \mathrm{NaCl}$ in a Stomacher Lab-blender 400 and homogenized. Appropriate serial dilutions were prepared from the same diluent. Unless otherwise indicated, $1 \mathrm{ml}$ aliquots of the diluted suspensions were mixed with molten $\left(45^{\circ} \mathrm{C}\right)$ medium and poured onto duplicate counting plates of the media described below.

Total aerobic and anaerobic bacteria were enumerated on plate count agar (PCA; Oxoid CM0035). Plates were incubated at $30^{\circ} \mathrm{C}$ for 1-2 days.

For the enumeration of bacterial spores, the first decimal dilution was pasteurized at $80^{\circ} \mathrm{C}$ for $10 \mathrm{~min}$ [5], and serially diluted. Then $100 \mu \mathrm{l}$ of the appropriate dilution was pour-plated onto PCA (Oxoid CM0035) topped with an additional layer of $1.5 \%$ bacteriological agar (Oxoid LP0011). All plates were prepared in duplicate and incubated at $37^{\circ} \mathrm{C}$ for $2-4$ days.
Fungi (yeasts and molds) were enumerated on Rose Bengal chloramphenicol agar (RBCA; Oxoid CM0549), to which $100 \mathrm{mg} / \mathrm{l}$ chloramphenicol (Oxoid SR0078E) was added [37]. Then $100 \mu \mathrm{l}$ of diluted suspensions were spread-plated onto this medium and incubated at $25^{\circ} \mathrm{C}$ for 2-4 days.

Duplicate counts were made for each of the duplicated samples, yielding four counts per sample. The results are reported as the means $\pm \mathrm{SD}(\mathrm{n}=4)$. For plates of bacterial spores containing around 100 colonies, the number of randomly selected isolates was the square root of the total number of colonies. Isolates were grown in nutrient broth (NB, Oxoid CM0001B) media under the conditions applied previously for plate counting.

\section{Identification of the Isolates by 16S rDNA Sequence Analyses}

Presumptive Bacillus spp. isolates were grown in nutrient broth medium supplemented with $\mathrm{MnCl}_{2}(50 \mathrm{mg} / \mathrm{l})$ to encourage sporulation. DNA was extracted from endospore-forming isolates using the Bacteria Genomic DNA Purification Kit (Tiangen, Beijing, China), according to the manufacturer's instructions. An approximately $1500 \mathrm{bp}$ fragment of the $16 \mathrm{~S}$ rDNA was amplified using forward primer B-for and reverse primer B-rev. The primers used in this study are shown in Table 1 . The sequencing of the 16S rDNA fragment was performed by Beijing Center for Physical and Chemical Analysis (Beijing, China). Sequence similarity was determined by accessing the BLAST database from GenBank.

\section{Identification by Culture-Independent Methods}

Total DNA extraction. For culture-independent investigations, $2 \mathrm{~g}$ of each Daqu sample was suspended in $30 \mathrm{ml}$ of PBS, and total DNA was extracted by a minor modification of the method of Wang et al. [29]. The collected DNA was air-dried and dissolved in $30 \mu \mathrm{l}$ of sterile water. DNA concentration was assayed by ultravioletvisible spectrophotometers (Unico, Shanghai, China) and diluted to an approximate final concentration of $10 \mathrm{ng} / \mu \mathrm{l}$.

PCR. The first PCR experiment adopted primers $\mathrm{pB} / \mathrm{pH}$ (Table 1), designed specifically for Bacillus and related genera (such as Alicyclobacillus, Brevibacillus, and Clostridium). The first PCR (referred to as "selective PCR") was performed in a $50 \mu \mathrm{l}$ reaction mixture containing $37.75 \mu \mathrm{l}$ of $\mathrm{ddH}_{2} \mathrm{O}, 5 \mu \mathrm{l}$ of PCR buffer, $4 \mu \mathrm{l}$ of dNTP $(2 \mathrm{mmol} / \mathrm{l}), 1 \mu \mathrm{l}$ of each primer $(10 \mu \mathrm{mol} / \mathrm{l}), 1 \mu \mathrm{l}$ of DNA template, and $0.25 \mu \mathrm{l}$ of Ex Taq DNA polymerase $(5 \mathrm{U} / \mu \mathrm{l})$ (Takara, Japan). PCR reactions were undertaken in a AG 223B1 Thermoblock (Eppendorf, NY, USA) with PCR conditions as follows: initial denaturation of double-stranded DNA for $5 \mathrm{~min}$ at $94^{\circ} \mathrm{C}$; 35 cycles,

Table 1. PCR primers used in this study.

\begin{tabular}{|c|c|c|c|}
\hline Primer & Sequence $\left(5^{\prime} \rightarrow 3^{\prime}\right)$ & Aims & Reference \\
\hline B-for $(F)$ & AACGCGAAGAACCTTAC & \multirow[t]{2}{*}{ Amplify $16 \mathrm{~S}$ rDNA and sequencing for bacteria } & \multirow[t]{2}{*}{ [16] } \\
\hline B-rev (R) & CGGTGTGTACAAGACCC & & \\
\hline $\mathrm{pB}(\mathrm{F})$ & CGATGCGTAGCCGACCTGAG & \multirow{2}{*}{$\begin{array}{l}\text { Amplify } 16 \mathrm{~S} \text { rDNA and sequencing especially } \\
\text { for Bacillus and related genera }\end{array}$} & \multirow[t]{2}{*}[2]{} \\
\hline $\mathrm{pH}(\mathrm{R})$ & AAGGAGGTGATCCAGCCGCA & & \\
\hline $\operatorname{Ec1055}(\mathrm{F})$ & ATGGCTGTCGTCAGCT & \multirow[t]{2}{*}{ DGGE PCR for Bacillus and related genera } & \multirow[t]{2}{*}[4]{} \\
\hline $\operatorname{Ec1392(R)}$ & $\begin{array}{l}\text { CGCCCGCCGCGCCCCGCGCCCGTCCCGC } \\
\underline{\text { CGCCCCCGCCCGACGGGCGGTGTGTAC }}\end{array}$ & & \\
\hline
\end{tabular}

$\mathrm{F}$, forward primer; $\mathrm{R}$, reversed primer. The GC clamp is underlined. 
each consisting of $30 \mathrm{sec}$ at $94^{\circ} \mathrm{C}, 45 \mathrm{sec}$ at $56^{\circ} \mathrm{C}$, and $90 \mathrm{sec}$ at $72^{\circ} \mathrm{C}$; and extension of incomplete products for $7 \mathrm{~min}$ at $72^{\circ} \mathrm{C}$, followed by cooling at $4^{\circ} \mathrm{C}$.

The product of this selective PCR was diluted to 1:100 and used as template for a second PCR (referred to as "DGGE PCR"), using primers Ec1055 and Ec1392 (Table 1). PCR was performed in a $50 \mu \mathrm{l}$ reaction mixture containing $37.75 \mu \mathrm{l}$ of $\mathrm{ddH}_{2} \mathrm{O}, 5 \mu \mathrm{l}$ of PCR buffer, $4 \mu \mathrm{l}$ of dNTP $(2 \mathrm{mmol} / \mathrm{l}), 1 \mu \mathrm{l}$ of each primer $(10 \mu \mathrm{mol} / \mathrm{l})$, $1 \mu \mathrm{l}$ of DNA template, and $0.25 \mu \mathrm{l}$ of Ex Taq DNA polymerase $(5 \mathrm{U} / \mu \mathrm{l})$ (Takara, Japan). PCR reactions were undertaken in a AG 223B1 Thermoblock (Eppendorf) with PCR conditions as follows: initial denaturation of double-stranded DNA for $5 \mathrm{~min}$ at $94^{\circ} \mathrm{C} ; 35$ cycles, each consisting of $30 \mathrm{sec}$ at $94^{\circ} \mathrm{C}, 45 \mathrm{sec}$ at $56^{\circ} \mathrm{C}$, and $1 \mathrm{~min}$ at $72^{\circ} \mathrm{C}$; and extension of incomplete products for $7 \mathrm{~min}$ at $72^{\circ} \mathrm{C}$ followed by cooling at $4^{\circ} \mathrm{C}$.

DGGE analyses. DGGE was performed using the Dcode system (Bio-Rad, Hercules, CA, USA) on $20 \mathrm{~cm} \times 16 \mathrm{~cm} \times 1 \mathrm{~mm}$ gels. Electrophoresis was performed at $60^{\circ} \mathrm{C}$ in $0.5 \times \mathrm{TAE}$ buffer $(20 \mathrm{mmol} / \mathrm{l}$ Tris-acetate, $2 \mathrm{mmol} / \mathrm{l}$ EDTA; $\mathrm{pH} 8.0$ ) using $8 \%$ polyacrylamide gels containing a $30-60 \%$ urea-formamide linear denaturing gradient [where $100 \%$ corresponds to $7 \mathrm{~mol} / 1$ urea and $40 \%$ (v/v) formamide]. Samples were run for $16 \mathrm{~h}$ at $85 \mathrm{~V}$.

Following electrophoresis, the gels were stained with $\mathrm{AgNO}_{3}$ solution as follows: The gel was fixed and shaken gently in $1 \times$ Cairn's fixation solution $(200 \mathrm{ml} 96 \%$ ethanol; $10 \mathrm{ml}$ acetic acid; $40 \mathrm{ml}$ demi-water) for $3 \mathrm{~min}$. The gel was transferred to a freshly made $\mathrm{AgNO}_{3}$ staining solution (2 $\mathrm{g} \mathrm{AgNO}_{3}$ per liter), shaken gently for $10 \mathrm{~min}$, and briefly rinsed in water. The stained gel was developed in a freshly made developing solution (10 $\mathrm{mg} \mathrm{NaBH}_{4}, 250 \mathrm{ml} 1.5 \%$ $\mathrm{NaOH}$ solution, $750 \mu$ l formaldehyde) until the desired exposure was achieved.

Bands of interest were excised from the gel and boiled for $30 \mathrm{~min}$, and then incubated overnight in $30 \mu \mathrm{l} 0.25 \times \mathrm{TAE}$ buffer $(10 \mathrm{mmol} / \mathrm{l}$ Tris-acetate, $1 \mathrm{mmol} / \mathrm{l} \mathrm{EDTA}$; $\mathrm{pH} 8.0$ ) at $4^{\circ} \mathrm{C}$ to allow diffusion of the DNA.

Sequencing of DGGE bands. Eluted DNA was re-amplified using the corresponding DGGE primers (Ec1055 and Ec1392), without the GC clamp. The PCR products were sequenced at the Beijing Center for Physical and Chemical Analysis (Beijing, China). Sequence identity was determined by accessing the nucleotide BLAST database of GenBank. To confirm the reproducibility of the DGGE fingerprints, the DNA isolated from the different DGGE bands was PCR-amplified three times.

\section{Determination of Antimicrobial Activity}

To examine the antimicrobial activity, 9 native $B$. licheniformis strains (YP-P-01, YP-P-02, YP-P-03, YP-P-04, YP-P-05, YP-P-07, YP-P-09, YP-P-11, YP-P-12) isolated at the end of Daqu incubation were used. B. licheniformis strains were grown in $100 \mathrm{ml}$ of NB (Oxoid CM0001B) at $37^{\circ} \mathrm{C}, 120 \mathrm{rpm}$ for $24 \mathrm{~h}$, respectively. Next, the cell-free supernatant was collected by centrifugation at $10,000 \mathrm{rpm}$ for $15 \mathrm{~min}$ at $4^{\circ} \mathrm{C}$.

The antimicrobial activities were investigated against 7 indicators of fungi and 11 indicators of bacteria (Table 4). All microorganisms were native microorganisms previously isolated from naturally fermented Daqu (Shanxi Xinghuacun Fenjiu Distillery Co. Ltd., Fenyang, Shanxi, China) and identified as described by Zheng et al. [37].

The agar diffusion assay described by Guo et al. [6] was used to test the antimicrobial activities of the cell-free supernatants. The indicator strains were grown at the corresponding conditions (Table 4) for 2-4 days. Sterile Oxford cups were placed on these agar plates and cell-free supernatant $(100 \mu \mathrm{l})$ of each B. licheniformis strain was added into each Oxford cup. After incubation for $12 \mathrm{~h}$ at the optimum growth temperature for the test organism, the presence of a clear zone around the cup (including that of the "Oxford cup" $7.8 \mathrm{~mm}$ ) was measured and the results were reported in $\mathrm{mm}$. The experiment was performed in duplicate on three separate occasions.

\section{RESULTS}

\section{Enumeration of Representative Bacteria and Fungi on Selective Media}

The culture-dependent methods, namely enumeration of bacteria, bacterial spores, and fungi, revealed gradual changes of within the microorganism community throughout Daqu incubation. Fig. 1 presents the dynamics of viable counts during the incubation, together with the temperatures of each sample at the respective stages of incubation. The total viable numbers of aerobic and anaerobic bacteria were significantly increased during all stages except $\mathrm{CH}$, where they were reduced. Initial counts of bacterial endospores were around $4 \log \mathrm{CFU} / \mathrm{g}$ (at the WQ stage), increasing rapidly to $9 \log \mathrm{CFU} / \mathrm{g}$ at the $\mathrm{HH}$ stage, and remaining constant thereafter. The total fungal counts increased rapidly from the initial WQ stage to SM, and then decreased (from LM to YQ). During the first three stages (WQ, SM, and LM), fungi presented in higher numbers than bacterial spores. After the $\mathrm{CH}$ stage, the bacterial spore counts exceeded those of fungi. Also from Fig. 1, we observe that the sample temperature increased from a mere $20^{\circ} \mathrm{C}$ at WQ to its maximal value of $55^{\circ} \mathrm{C}$ at $\mathrm{HH}$. Following the $\mathrm{HH}$ stage, the temperature hovered around $30^{\circ} \mathrm{C}$, apart from a curiously anomalous slight dip at the LM stage.

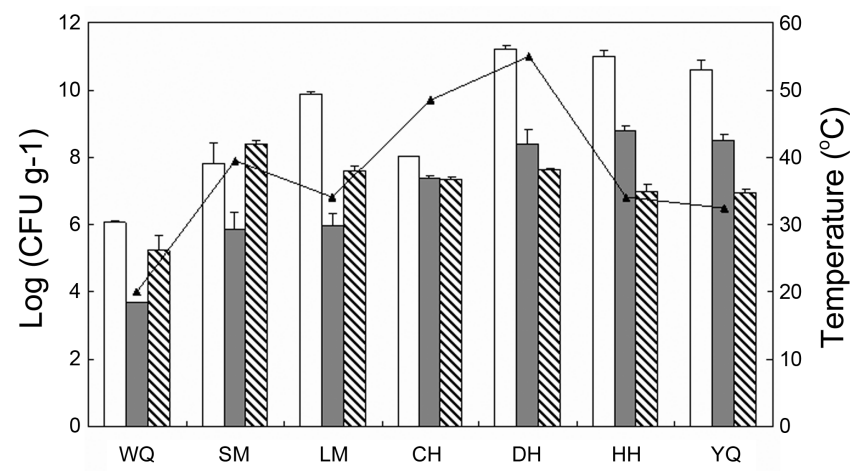

Fig. 1. Microbial community composition and temperatures at each stage of Daqu incubation.

WQ: Woqu; SM: Shangmei; LM: Liangmei; CH: Chaohuo; DH: Dahuo; HH: Houhuo; YQ: Yangqu. $\square$ : Total Viable Count; $\square$ : Sport-forming Bacteria; MIV: Fungi; $\mathbf{\Lambda}$ : Temperature. 
Table 2. Species-level identification of 52 isolates $(\mathrm{n}=67)$ based on partial $16 \mathrm{~S}$ rDNA sequencing of the Daqu samples.

\begin{tabular}{|c|c|c|c|c|}
\hline Step & Sample code & Sequencing & Accession no. & $\%$ Identity \\
\hline \multirow{5}{*}{$\begin{array}{c}\text { WQ } \\
(\mathrm{n}=8 \\
\mathrm{k}=5)\end{array}$} & WQ-P-02 & Bacillus licheniformis & AB553280.1 & 99 \\
\hline & WQ-P-03 & Bacillus licheniformis & EU379276.1 & 99 \\
\hline & WQ-P-05 & Bacillus licheniformis & HМ006908.1 & 99 \\
\hline & WQ-P-06 & Bacillus licheniformis & GU967452.1 & 100 \\
\hline & WQ-P-07 & Bacillus pumilus & GU125637.1 & 99 \\
\hline \multirow{7}{*}{$\begin{array}{c}\text { SM } \\
(\mathrm{n}=8 \\
\mathrm{k}=7)\end{array}$} & SM-P-01 & Bacillus licheniformis & AY871102.1 & 99 \\
\hline & SM-P-02 & Bacillus pumilus & EU379276.1 & 100 \\
\hline & SM-P-03 & Bacillus pumilus & GU290547.1 & 99 \\
\hline & SM-P-04 & Bacillus licheniformis & GU967452.1 & 99 \\
\hline & SM-P-05 & Bacillus licheniformis & GQ222400.1 & 99 \\
\hline & SM-P-06 & Bacillus licheniformis & AY871102.1 & 99 \\
\hline & SM-P-07 & Bacillus subtilis & EF032678.1 & 99 \\
\hline \multirow{9}{*}{$\begin{array}{c}\text { LM } \\
(\mathrm{n}=11 \\
\mathrm{k}=9)\end{array}$} & LM-P-01 & Bacillus pumilus & GU084168.1 & 99 \\
\hline & LM-P-02 & Bacillus licheniformis & GU967452.1 & 100 \\
\hline & LM-P-03 & Bacillus licheniformis & GU967452.1 & 99 \\
\hline & LM-P-04 & Bacillus pumilus & GU084168.1 & 100 \\
\hline & LM-P-05 & Bacillus cereus & GQ199590.1 & 99 \\
\hline & LM-P-06 & Bacillus cereus & GQ355961.1 & 99 \\
\hline & LM-P-08 & Bacillus megaterium & DQ105968.1 & 99 \\
\hline & LM-P-10 & Bacillus megaterium & DQ105968.1 & 99 \\
\hline & LM-P-11 & Bacillus anthracis & СР001598.1 & 99 \\
\hline \multirow{6}{*}{$\begin{array}{c}\mathrm{CH} \\
(\mathrm{n}=9 ; \\
\mathrm{k}=6)\end{array}$} & CH-P-01 & Bacillus licheniformis & AY871102.2 & 99 \\
\hline & CH-P-03 & Bacillus licheniformis & GU967452.1 & 99 \\
\hline & CH-P-04 & Bacillus megaterium & EU931553.1 & 99 \\
\hline & CH-P-05 & Bacillus licheniformis & GU967452.1 & 99 \\
\hline & CH-P-06 & Bacillus circulans & AY043084.1 & 99 \\
\hline & CH-P-08 & Bacillus licheniformis & GU967449.1 & 100 \\
\hline \multirow{9}{*}{$\begin{array}{c}\text { DH } \\
(n=10 \\
k=9)\end{array}$} & DH-P-01 & Bacillus licheniformis & FJ435674.1 & 99 \\
\hline & DH-P-02 & Bacillus licheniformis & AB374301.1 & 99 \\
\hline & DH-P-03 & Bacillus licheniformis & GU967449.1 & 99 \\
\hline & DH-P-04 & Bacillus licheniformis & GU967452.1 & 99 \\
\hline & DH-P-05 & Bacillus licheniformis & HМ055609.1 & 99 \\
\hline & DH-P-06 & Bacillus licheniformis & GU967452.1 & 99 \\
\hline & DH-P-07 & Bacillus licheniformis & DQ870721.1 & 100 \\
\hline & DH-P-08 & Bacillus licheniformis & GU967452.1 & 100 \\
\hline & DH-P-09 & Bacillus licheniformis & СР001598.1 & 99 \\
\hline \multirow{6}{*}{$\begin{array}{c}\mathrm{HH} \\
(\mathrm{n}=9 ; \\
\mathrm{k}=6)\end{array}$} & HН-P-02 & Bacillus licheniformis & HМ006868.1 & 99 \\
\hline & HН-P-03 & Bacillus licheniformis & GU967449.1 & 100 \\
\hline & HН-P-04 & Bacillus pumilus & EU379276.1 & 100 \\
\hline & HН-P-06 & Bacillus licheniformis & AB553280.1 & 99 \\
\hline & HН-P-07 & Bacillus licheniformis & AF276309.1 & 99 \\
\hline & НH-P-09 & Bacillus pumilus & GQ903421.1 & 98 \\
\hline \multirow{10}{*}{$\begin{array}{c}\mathrm{YQ} \\
(\mathrm{n}=12 \\
\mathrm{k}=10)\end{array}$} & YQ-P-01 & Bacillus licheniformis & GU967449.1 & 99 \\
\hline & YQ-P-02 & Bacillus licheniformis & AY750906.1 & 99 \\
\hline & YQ-P-03 & Bacillus licheniformis & GQ222400.1 & 99 \\
\hline & YQ-P-04 & Bacillus licheniformis & GU967449.1 & 100 \\
\hline & YQ-P-05 & Bacillus licheniformis & EF472268.1 & 99 \\
\hline & YQ-P-07 & Bacillus licheniformis & GU967449.1 & 100 \\
\hline & YQ-P-08 & Bacillus amyloliquefaciens & EU257436 & 99 \\
\hline & YQ-P-09 & Bacillus licheniformis & GQ222400.1 & 99 \\
\hline & YQ-P-11 & Bacillus licheniformis & GU967449.1 & 99 \\
\hline & YQ-P-12 & Bacillus licheniformis & AY8971102.1 & 100 \\
\hline
\end{tabular}

WQ: Woqu; SM: Shangmei; LM: Liangmei; CH: Chaohuo; DH: Dahuo; HH: Houhuo; YQ: Yangqu. $\mathrm{n}=$ the total number of isolates; $\mathrm{k}=$ the total number of isolates identified as Bacillus. 


\section{Identification of the Bacterial Isolates}

Table 2 lists the identified Bacillus species based on partial sequence alignment of $16 \mathrm{~S}$ rDNA at each stage. Of the 67 isolates, 52 were identified as Bacillus by $16 \mathrm{~S}$ rDNA sequence comparison against the BLAST database entries; the remaining isolates comprised Staphylococcus and Acetobacter spp. Most of the sequenced isolates showed high similarity $(99-100 \%)$ to GenBank sequences. The identified Bacillus organisms belonged to 8 species: $B$. licheniformis, B. subtilis, B. amyloliquefaciens, B. cereus, B. circulans, B. megaterium, B. pumilus, and B. anthracis. From Table 2, it is seen that $B$. licheniformis predominated throughout Daqu incubation, representing approximately $70 \%$ of all isolates. The Bacillus community was most diverse at the LM stage with five different species detected, most of which declined to undetectable levels in successive production stages.

\section{DGGE Analyses}

The DGGE patterns of the production stages are presented in Fig. 2. Label identifications are provided in Table 3. The results of the two approaches generally coincide. Total DNA extracted from each Daqu incubation stage was used in a nest-PCR with primers $\mathrm{pB} / \mathrm{pH}$ (selective PCR) and Ec1055/Ec1392 (DGGE PCR), to amplify a section of the V9 region of the 16S rDNA for DGGE analyses. A characteristic snapshot of the band patterns is shown in Fig. 2, and the closest GenBank relatives of selected

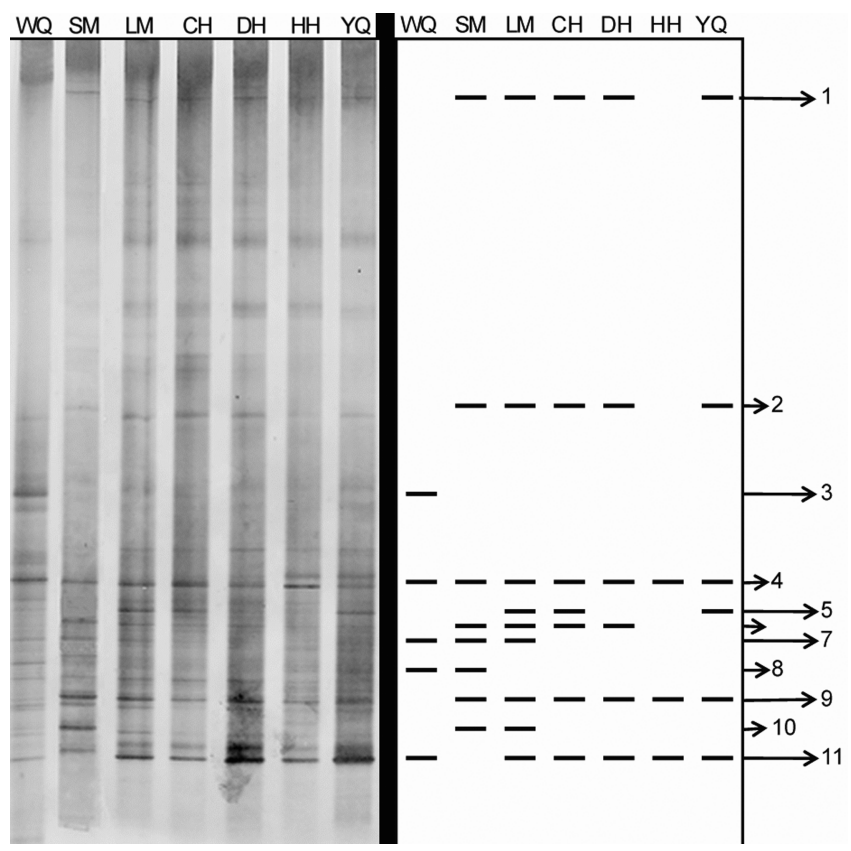

Fig. 2. DGGE profiles (30-60\% denaturant) representing $16 \mathrm{~S}$ rDNA fragments of the Daqu samples.

Bands excised from the gel and sequenced (see also Table 3) are numbered.
DGGE bands are shown in Table 3. PCR-DGGE analyses of Daqu DNA confirmed the presence of the easily cultured species, besides revealing several uncultured Bacillus spp.

Eleven bands were resolved in the PCR-DGGE analysis, corresponding to 6 species: $B$. subtilis, B. amyloliquefaciens, $B$. licheniformis, B. pumilus, B. benzoevorans, and $B$. foraminis. Uncultured Bacillus and other genera were also detected by DGGE. The diversity of Bacillus increased from WQ to LM, reaching a maximum of 9 species at the LM stage, after which the diversity decreased until the end of the incubation. B. licheniformis was detected at every stage of the incubation, as evidenced by a very intense DGGE band migrating approximately to the end of the DGGE gels. We infer that $B$. licheniformis is a dominant species throughout the entire incubation period. Other Bacillus spp. were detected only at specific stages of the incubation. B. subtilis was present at all stages except the WQ stage. B. amyloliquefaciens was present at all stages except the SM stage. B. pumilus was only found at the LM, $\mathrm{CH}$, and YQ stages, whereas $B$. benzoevorans was absent from the WQ, HH, and YQ stages. B. foraminis was only found at the WQ, SM, and LM stages. Band No. 2 in Fig. 2 was strong everywhere except at the WQ and HH stages. Unfortunately, this band could not be resolved.

\section{Antimicrobial Spectra of B. licheniformis Strains}

Antimicrobial activities of the cell-free supernatants of $B$. licheniformis strains against several bacterial, fungal, and yeast strains were tested (Table 5). Only the cell-free supernatants of YQ-P-02, YQ-P-05, and YQ-P-12 did not inhibit all the indicators. The cell-free supernatants of YQP-01, YQ-P-04, YQ-P-07, and YQ-P-11 showed inhibition of several indicators, including $B$. cereus LM-P-05, $B$. subtilis SM-P-07, S. epidermidis YQ-P-10, E. coli SM-V02 , and $S$. enterica WQ-M-06. The cell-free supernatants of YQ-P-03 and YQ-P-09 only inhibited S. epidermidis YQ-P-10, E. coli SM-V-02, and S. enterica WQ-M-06. All

Table 3. Sequence analyses of PCR-DGGE-generated bands from V9 amplification of the Daqu samples.

\begin{tabular}{cllc}
\hline $\begin{array}{c}\text { Band } \\
\text { no. }\end{array}$ & Closet relative in GenBank & $\begin{array}{c}\text { Accession } \\
\text { no. }\end{array}$ & $\begin{array}{c}\% \\
\text { Identity }\end{array}$ \\
\hline 1 & Uncultured bacilli bacterium & JF733120.1 & 97 \\
2 & No sequence & & \\
3 & Uncultured Bacillus sp. & GU936825.1 & 100 \\
4 & Bacillus licheniformis & AY871103.1 & 99 \\
5 & Bacillus pumilus & EU379276.1 & 100 \\
6 & Bacillus benzoevorans & NR_044828.1 & 98 \\
7 & Bacillus foraminis & GQ903409.1 & 99 \\
8 & Uncultured bacterium & FM873507.1 & 100 \\
9 & Bacillus subtilis & HQ694497.1 & 100 \\
10 & Bacillus sp. & FN397517.1 & 100 \\
11 & Bacillus amyloliquefaciens & JN559885.1 & 100 \\
\hline
\end{tabular}


Table 4. Indicator microorganisms.

\begin{tabular}{|c|c|c|}
\hline Indicators & Growth media $^{a}$ & Growth temperature \\
\hline \multicolumn{3}{|l|}{ Yeast } \\
\hline Pichia kudriavzevii LM-05 & Malt extract agar & $25^{\circ} \mathrm{C}$ \\
\hline Saccharomyces cerevisiae WQ-11 & Malt extract agar & $25^{\circ} \mathrm{C}$ \\
\hline Saccharomycopsis fibuligera SM-03 & Malt extract agar & $25^{\circ} \mathrm{C}$ \\
\hline Wickerhamomyces anomalus WQ-10 & Malt extract agar & $25^{\circ} \mathrm{C}$ \\
\hline \multicolumn{3}{|l|}{ Filamentous fungi } \\
\hline Absidia corymbifera $\mathrm{HH}-07$ & Malt extract agar & $30^{\circ} \mathrm{C}$ \\
\hline Rhizomucor pusillus HH-05 & Malt extract agar & $30^{\circ} \mathrm{C}$ \\
\hline Rhizopus stolonifer SM-02 & Malt extract agar & $30^{\circ} \mathrm{C}$ \\
\hline \multicolumn{3}{|l|}{ Gram-positive bacteria } \\
\hline B. cereus LM-P-05 & Nutrient agar & $37^{\circ} \mathrm{C}$ \\
\hline B. pumilus WQ-P-07 & Nutrient agar & $37^{\circ} \mathrm{C}$ \\
\hline B. subtilis SM-P-07 & Nutrient agar & $37^{\circ} \mathrm{C}$ \\
\hline Lactobacillus plantarum LM-M-02 & MRS agar & $37^{\circ} \mathrm{C}$ \\
\hline Micrococcus luteus LM-M-01 & Nutrient agar & $30^{\circ} \mathrm{C}$ \\
\hline Staphylococcus epidermidis YQ-P-10 & Nutrient agar & $37^{\circ} \mathrm{C}$ \\
\hline \multicolumn{3}{|l|}{ Gram-negative bacteria } \\
\hline Acetobacter tropicalis CH-P-02 & Nutrient agar & $37^{\circ} \mathrm{C}$ \\
\hline Escherichia coli SM-V-02 & Nutrient agar & $37^{\circ} \mathrm{C}$ \\
\hline Pediococcus pentosaceus YQ-M-10 & Brain-heart infusion agar & $37^{\circ} \mathrm{C}$ \\
\hline Pseudomonas aeruginosa SM-M-04 & Nutrient agar & $37^{\circ} \mathrm{C}$ \\
\hline Salmonella enterica WQ-M-06 & Brain-heart infusion agar & $37^{\circ} \mathrm{C}$ \\
\hline
\end{tabular}

${ }^{\mathrm{a} B r a i n}$-heart infusion (BHI) agar containing BHI broth (Oxoid CM0225) and 1.5\% of bacteriological agar (Oxoid LP0011) (pH 7.0); Malt extract agar (MEA, Oxoid CM0059); MRS agar (Oxoid CM0361); Nutrient agar (Oxoid CM0003).

Table 5. Antimicrobial spectra of cell-free supernatants of $B$. licheniformis strains.

\begin{tabular}{|c|c|c|c|c|c|c|c|c|c|}
\hline \multirow[t]{3}{*}{ Indicators } & \multicolumn{9}{|c|}{ Antimicrobial activity } \\
\hline & \multicolumn{9}{|c|}{ B. licheniformis strains } \\
\hline & YQ-P-01 & YQ-P-02 & YQ-P-03 & YQ-P-04 & YQ-P-05 & YQ-P-07 & YQ-P-09 & YQ-P-11 & YQ-P-12 \\
\hline \multicolumn{10}{|l|}{ Yeast } \\
\hline P. kudriavzevii LM-05 & - & - & - & - & - & - & - & - & - \\
\hline S. cerevisiae WQ-11 & - & - & - & - & - & - & - & - & - \\
\hline S. fibuligera SM-03 & - & - & - & - & - & - & - & - & - \\
\hline W. anomalus WQ-10 & - & - & - & - & - & - & - & - & - \\
\hline \multicolumn{10}{|l|}{ Filamentous fungi } \\
\hline A. corymbifera $\mathrm{HH}-07$ & - & - & - & - & - & - & - & - & - \\
\hline R. pusillus $\mathrm{HH}-05$ & - & - & - & - & - & - & - & - & - \\
\hline R. stolonifer $\mathrm{SM}-02$ & - & - & - & - & - & - & - & - & - \\
\hline \multicolumn{10}{|l|}{ Gram-positive bacteria } \\
\hline B. cereus LM-P-05 & + & - & - & ++ & - & + & - & + & - \\
\hline B. pumilus WQ-P-07 & - & - & - & - & - & - & - & - & - \\
\hline B. subtilis SM-P-07 & + & - & - & + & - & + & - & + & - \\
\hline L. plantarum LM-M-02 & - & - & - & - & - & - & - & - & - \\
\hline M. luteus LM-M-01 & - & - & - & - & - & - & - & - & - \\
\hline S. epidermidis YQ-P-10 & ++ & - & + & ++ & - & ++ & + & ++ & - \\
\hline \multicolumn{10}{|l|}{ Gram-negative bacteria } \\
\hline A. tropicalis $\mathrm{CH}-\mathrm{P}-02$ & - & - & - & - & - & - & - & - & - \\
\hline E. coli $\mathrm{SM}-\mathrm{V}-02$ & ++ & - & + & ++ & - & ++ & + & ++ & - \\
\hline P. pentosaceus YQ-M-10 & - & - & - & - & - & - & - & - & - \\
\hline P. aeruginosa SM-M-04 & - & - & - & - & - & - & - & - & - \\
\hline S. enterica WQ-M-06 & ++ & - & + & ++ & - & + & ++ & ++ & - \\
\hline
\end{tabular}

-, Not detectable; +, diameter of inhibitory zone smaller than $10 \mathrm{~mm}$; ++, diameter of inhibitory zone between 10 and $15 \mathrm{~mm}$. 
the fungal and yeast strains were not inhibited by cell-free supernatants of the nine $B$. licheniformis strains.

\section{DisCUSSION}

Currently, the investigation of microbial associations in fermentation foods attracts substantial interest. Recent studies have focused on the preferential growth of particular organisms and the spontaneous succession of microbial communities [7,20]. During Daqu incubation, these microbial associations have been developed and controlled by traditional fermentation technologies. The microbiota changes throughout Daqu incubation are important for stabilizing Daqu and elucidating the underlying microbiological processes. By understanding these processes, it will become possible to improve the quality and shelf-life of Daquderived products. To date, however, the microbiota of Daqu has received little attention. In particular, the ecology of Bacillus throughout Daqu incubation has not been reported, despite its reputation as a dominant genus in $D a q u$. The objective of this study was to bridge this knowledge gap using a combination of culture-dependent and culture-independent methods. In general, the Daqu Bacillus community is relatively diverse, with 8 species detected by culture-dependent methods, and 7 species (including uncultured Bacillus sp.) by culture-independent methods. This is not surprising since Daqu is produced by uncontrolled natural fermentation.

This study reveals that Bacillus spp. are continuously present throughout Daqu incubation, and follow a succession, consistent with the results of Shi et al. [22] and Zheng et al. [37]. Bacillus spp. are versatile and can adapt to diverse $\mathrm{pH}$, temperature, and nutrient conditions [10]. Throughout the incubation, the temperature increases gradually, attaining a maximum of $55^{\circ} \mathrm{C}$, as shown in Fig. 1. Such temperatures should have a selective effect on the microbiota, favoring thermotolerant, aerobic endosporeforming bacteria. Because the genus Bacillus possesses all of these characteristics, it can persist and rapidly overtake the fungi (which are more numerous at the start of incubation). The antimicrobial activities of Bacillus may be another reason why Bacillus strains become dominant in Daqu $[12,24]$. Although Daqu is not reported to have strong antimicrobial activity, certain $B$. licheniformis strains isolated from Daqu showed antimicrobial activities. From our study, the antimicrobial spectra of the $B$. licheniformis strains are not broad, concentrating on certain bacteria. This may explain why many microorganisms can still be isolated after Daqu incubation [28, 37, 38]. Or after living together for a long time, the microorganisms in Daqu might have adapted to one another.

In this study, we also observed that viable Bacillus cells increase up to the DH stage while the diversity declines.
The highest Bacillus diversity emerged at the LM stage. The conditions during the LM stage are probably favorable to most of the Bacillus species in Daqu. As the microenvironment of the fermenting substrate changes, species occurring in low numbers are often out-competed by more abundant species and become undetectable. In this study, B. licheniformis, B. subtilis, B. pumilus, and B. amyloliquefaciens were identified by both culture-dependent and culture-independent methods. These four species have been reported to exist in other Daqu $[25,28,32]$. However, the occurrence of $B$. circulans, $B$. anthracis, $B$. benzoevorans, and B. foraminis has not been reported in Daqu to date. Unknown Bacillus species, indicated as "uncultured," were also detected in our study.

Traditionally, Bacillus species have been associated with food spoilage. They reduce the quality and safety of food. More recently, however, they have been linked to fermentation processes in foods such as tape ketan, cocoa, kinema, and mеju [10, 17]. Bacillus appears to produce thermostable enzymes that degrade cell walls and other polysaccharides, and may be implicated in flavor development and precursors such as pyrazines. Good examples are some African and Asian fermented dishes such as African locust bean, Thua nao, and Bikalga [9, 19]. The production of these enzymes and aroma precursors is also beneficial to Daqu and its derived products [30,35], although the extent to which Bacillus contributes to the texture and flavor development of these products is unknown. Therefore, elucidating the ecology of Bacillus in Daqu is useful not only to standardize Daqu incubation, but also to optimize the quality and safety of its derived products [13].

PCR-DGGE is a powerful technique that can analyze microbial ecology in uncultivated complex microbial communities [8]. Nevertheless, it is subject to misinterpretation arising from incomplete DNA extraction, PCR biases, comigration, and poor resolution of low abundance microbes. Generally, bacterial populations comprising $1 \%$ or more of the total community are detectable by DGGE [31]. This may explain why $B$. megaterium, $B$. cereus, $B$. circulans, and $B$. anthracis were not observed in DGGE, but were found by isolation. These species were likely present in minimal proportions in the samples $(<1 \%)$. It should also be noted that PCR-DGGE methods detect dead as well as viable cells. Furthermore, the two sampling methods are not the same. The culture-dependent approach measures the germinated spores, determined both by the abundance of spore species and their ability to germinate. By contrast, the culture-independent approach relies on ample DNA extraction of all microorganisms in the sample. These differences will almost certainly contribute to some of the differences found in the diversity of Bacillus.

The flavors of Daqu-derived products differ with geographical locations [38]. The specific microbial composition of Daqu is known to play a key role in the 
flavor of its derived products $[25,28,36,38]$. B. subtilis is a dominant microorganism in Moutai Daqu and heavily influences the flavor of Moutai liquor [23, 26, 33]. In this study, $B$. licheniformis was established as the predominant bacterium in Daqu produced by the Shanxi Xinghuacun Fenjiu Distillery Co. Ltd. China (Fen Daqu). Liu et al. [15] arrived at the same conclusion using culture-dependent methods. B. licheniformis is a facultative anaerobe bacterium, able to grow under adverse ecological conditions. It has been implicated in the production of neutral protease in Fuqu (another kind of $Q u$ ) [34]. The bacterium may produce more than 70 metabolites, most of which are flavoring compounds and flavoring precursors used in the liquor industry [27]. More detailed investigations are required to reveal the impact of $B$. licheniformis on the flavor development in Fen Daqu and its derived products.

In conclusion, Bacillus is dominant and active throughout the seven stages of Daqu incubation, and we expect that Bacillus species will largely affect the texture and flavor of Daqu. B. licheniformis was detected at all stages of the incubation by both culture-dependent and cultureindependent methods, and was therefore regarded as the persistent dominant Bacillus species. We expect this specie to mainly affect the quality of Daqu. The impact of $B$. licheniformis on the stabilization, quality and safety of Daqu and its derived products will emerge under further investigation.

\section{Acknowledgments}

This work was supported by the National Natural Foundation of China (No. 31071592), the KNAW China Joint Research Project 07CDP015 funded by the Royal Netherlands Academy of Arts and Sciences, and the Fundamental Research Funds for the Central Universities (No. 2010JS076).

\section{REFERENCES}

1. Baril, E., L. Coroller, O. Couvert, I. Leguérinel, F. Postollec, C. Boulais, et al. 2012. Modeling heat resistance of Bacillus weihenstephanensis and Bacillus licheniformis spores as function of sporulation temperature and pH. Food Microbiol. 30: 29-36.

2. De Clerck, E., D. Gevers, K. De Ridder, and P. De Vos. 2004. Screening of bacterial contamination during gelatine production by means of denaturing gradient gel electrophoresis, focussed on Bacillus and related endospore-forming genera. J. Appl. Microbiol. 96: 1333-1341.

3. Fernández-No, I. C., M. Guarddon, K. Böhme, A. Cepeda, P. Calo-Mata, and J. Barros-Velázquez. 2011. Detection and quantification of spoilage and pathogenic Bacillus cereus, Bacillus subtilis and Bacillus licheniformis by real-time PCR. Food Microbiol. 28: 605-610.
4. Ferris, M., G. Muyzer, and D. Ward. 1996. Denaturing gradient gel electrophoresis profiles of 16S rRNA-defined populations inhabiting a hot spring microbial mat community. Appl. Environ. Microbiol. 62: 350-356.

5. Garbeva, P., J. A. van Veen, and J. D. van Elsas. 2003. Predominant Bacillus spp. in agricultural soil under different management regimes detected via PCR-DGGE. Microb. Ecol. 45: 302-316.

6. Guo, Y., Z. Yu, J. Xie, and R. Zhang. 2012. Identification of a new Bacillus licheniformis strain producing a bacteriocin-like substance. J. Microbiol. 50: 452-458.

7. Haruta, S., S. Ueno, I. Egawa, K. Hashiguchi, A. Fujii, M. Nagano, et al. 2006. Succession of bacterial and fungal communities during a traditional pot fermentation of rice vinegar assessed by PCR-mediated denaturing gradient gel electrophoresis. Int. J. Food Microbiol. 109: 79-87.

8. Iacumin, L., F. Cecchini, M. Manzano, M. Osualdini, D. Boscolo, S. Orlic, and G. Comi. 2009. Description of the microflora of sourdoughs by culture-dependent and culture-independent methods. Food Microbiol. 26: 128-135.

9. Inatsu, Y., N. Nakamura, Y. Yuriko, T. Fushimi, L. Watanasiritum, and S. Kawamoto. 2006. Characterization of Bacillus subtilis strains in Thua nao, a traditional fermented soybean food in northern Thailand. Lett. Appl. Microbiol. 43: 237-242.

10. Jung, J., M. Lee, and H. Chang. 2012. Evaluation of the probiotic potential of Bacillus polyfermenticus CJ6 isolated from meju, a Korean soybean fermentation starter. J. Microbiol. Biotechnol. 22: 1510-1517.

11. Karim, M., and M. Azin. 2011. Production of alkaline protease by entrapped Bacillus licheniformis cells in repeated batch process. J. Microbiol. Biotechnol. 21: 1250-1256.

12. Kim, Y., J. Y. Cho, J. H. Kuk, J. H. Moon, J. I. Cho, Y. C. Kim, and K. H. Park. 2004. Identification and antimicrobial activity of phenylacetic acid produced by Bacillus licheniformis isolated from fermented soybean, chungkook-jang. Curr. Microbiol. 48: 312-317.

13. Li, X. R., E. B. Ma, L. Z. Yan, H. Meng, X. W. Du, S. W. Zhang, and Z. X. Quan. 2011. Bacterial and fungal diversity in the traditional Chinese liquor fermentation process. Int. J. Food Microbiol. 146: 31-37.

14. Lima, L. J. R., H. J. Kamphuis, M. J. R. Nout, and M. H. Zwietering. 2011. Microbiota of cocoa powder with particular reference to aerobic thermoresistant spore-formers. Food Microbiol. 28: $573-582$.

15. Liu, G. J., T. T. Zhu, H. X. Liu, Z. X. Wen, J. H. Hu, W. J. Hao, and L. Y. Li. 2010. Isolation and identification of Bacillus licheniformis from Fen-flavor Daqu starters and the fermented grains. Liquor Making Sci. Technol. 187: 31-36 [in Chinese].

16. Niemann, S., A. Pühler, H. V. Tichy, R. Simon, and W. Selbitschka. 1997. Evaluation of the resolving power of three different DNA fingerprinting methods to discriminate among isolates of a natural Rhizobium meliloti population. J. Appl. Microbiol. 82: 477-484.

17. Ouattara, H., B. Koffi, G. Karou, A. Sangaré, S. Niamke, and J. Diopoh. 2008. Implication of Bacillus sp. in the production of pectinolytic enzymes during cocoa fermentation. World $J$. Microbiol. Biotechnol. 24: 1753-1760.

18. Ouattara, H. G., S. Reverchon, S. L. Niamke, and W. Nasser. 2011. Molecular identification and pectate lyase production by 
Bacillus strains involved in cocoa fermentation. Food Microbiol. 28: $1-8$.

19. Ouoba, L. I. I., C. Parkouda, B. Diawara, C. Scotti, and A. H. Varnam. 2008. Identification of Bacillus spp. from Bikalga, fermented seeds of Hibiscus sabdariffa: Phenotypic and genotypic characterization. J. Appl. Microbiol. 104: 122-131.

20. Ryun, K. H. and J. H. Kim. 2012. Microbial dynamics of commercial makgeolli depending on the storage temperature. $J$. Microbiol. Biotechnol. 22: 1101-1106.

21. Sharma, S. K., M. P. Sharma, A. Ramesh, and O. P. Joshi. 2012. Characterization of zinc-solubilizing Bacillus isolates and their potential to influence zinc assimilation in soybean seeds. $J$. Microbiol. Biotechnol. 22: 352-359.

22. Shi, J. H., Y. P. Xiao, X. R. Li, E. B. Ma, X. W. Du, and Z. X. Quan. 2009. Analyses of microbial consortia in the starter of Fen liquor. Lett. Appl. Microbiol. 48: 478-485.

23. Shi, X. M., Y. Xu, F. Y. Cui, Y. Y. Zhong, Y. Q. Xie, and X. Xie. 2012. Study on the application of Bacillus subtilis in the production of liquor. Liquor Making Sci. Technol. 212: 49-53 [in Chinese].

24. Velmurugan, N., M. Choi, S. S. Han, and Y. S. Lee. 2009. Evaluation of antagonistic activities of Bacillus subtilis and Bacillus licheniformis against wood-staining fungi: In vitro and in vivo experiments. J. Microbiol. 47: 385-392.

25. Wang, C. L., D. J. Shi, and G. L. Gong. 2008. Microorganisms in Daqu: A starter culture of Chinese Maotai-flavor liquor. World J. Microbiol. Biotechnol. 24: 2183-2190.

26. Wang, H. Y., F. Yang, C. P. Yao, L. Lin, L. Wang, Y. Lu, and K. Ji. 2009. Analysis and comparison of the metabolites produced by a strain of Bacillus subtilis by use of two different mediums. Liquor Making Sci. Technol. 186: 93-95 [in Chinese].

27. Wang, H., F. Yang, L. Lin, L. Wang, D. Yang, Y. Lu, and K. Ji. 2011. Analysis of the metabolites of Bacillus licheniformis by solid fermentation. Liquor Making Sci. Technol. 207: 32-35 [in Chinese].

28. Wang, H. Y., Y. B. Gao, Q. W. Fan, and Y. Xu. 2011. Characterization and comparison of microbial community of different typical Chinese liquor Daqus by PCR-DGGE. Lett Appl. Microbiol. 53: 135-140.
29. Wang, H. Y., X. J. Zhang, L. P. Zhao, and Y. Xu. 2008. Analysis and comparison of the bacterial community in fermented grains during the fermentation for two different styles of Chinese liquor. J. Ind. Microbiol. Biotechnol. 35: 603-609.

30. Wang, Y. M. and Y. L Zhao. 2002. Effects of Bacillus species on the flavour of Fenjiu liquor. Liquor Making Sci. Technol. 113: 31-32 [in Chinese].

31. Weisburg, W. G., S. M. Barns, D. A. Pelletier, and D. J. Lane. 1991. 16S Ribosomal DNA amplification for phylogenetic study. J. Bacteriol. 173: 697-703.

32. Xiu, L., G. Kunliang, and Z. Hongxun. 2012. Determination of microbial diversity in Daqu, a fermentation starter culture of Maotai liquor, using nested PCR-denaturing gradient gel electrophoresis. World J. Microbiol. Biotechnol. 28: 2375-2381.

33. Yang, F., H. Y. Wang, C. P. Yao, L. Lin, L. Wang, Y. Lu, and K. Ji. 2010. The difference and the similarities in metabolites of Bacillus subtilis strains by different techniques. Liquor Making Sci. Technol. 187: 104-106 [in Chinese].

34. Yuan, C., L. F. Cui, and R. M. Wang. 2011. Study on the fermentation conditions of Bacillus licheniformis in bran starter to produce neutral protease. Liquor Making Sci. Technol. 201: 40-42 [in Chinese].

35. Zhang, W. X., Z. Y. Wu, Q. S. Zhang, R. Wang, and H. Li. 2009. Combination of newly developed high quality Fuqu with traditional Daqu for Luzhou-flavor liquor brewing. World J. Microbiol. Biotechnol. 25: 1721-1726.

36. Zhao, S., C. X. Yang, S. Dou, M. Xu, and Y. H. Liao. 2012. Research advance about microbes in Chinese liquor production. China Brew. 31: 5-10 [in Chinese].

37. Zheng, X. W., Z. Yan, B. Z. Han, M. H. Zwietering, R. A. Samson, T. Boekhout, and M. J. R. Nout. 2012. Complex microbiota of a Chinese "Fen" liquor fermentation starter (FenDaqu), revealed by culture-dependent and culture-independent methods. Food Microbiol. 31: 293-300.

38. Zheng, X. W., M. R. Tabrizi, M. J. R. Nout, and B. Z. Han. 2011. Daqu - A traditional Chinese liquor fermentation starter. J. Inst. Brew. 117: 82-90. 